\title{
Researchers' Toolbox for the Future: Empowering Children To Shape Their
} Future

\author{
SIRKKU KOTILAINEN, JUSSI OKKONEN, GUNA SPURAVA \\ Faculty of Information Technology and Communication Sciences, Tampere University, Finland.
}

\section{OLE SEJER IVERSEN}

Center for Computational Thinking and Design, Aarhus University, Denmark.

NETTA IIVARI, MARIANNE KINNULA, SUMITA SHARMA

INTERACT Research Unit, University of Oulu, Finland. firstname.lastname@oulu.fi

There is an increasing emphasis on empowering children through co-design and co-creation of technology that shapes their learning, wellbeing and lifestyle, and everyday lived experiences. However, several questions emerge: what does it really mean to empower children, what have we achieved thus far, and where are we headed now, as we fight the ongoing pandemic, and in the future when the pandemic is behind us? This workshop aims to answer such questions by investigating, through a strategy approach, different forms of empowerment of children and related ethical, practical, political, and technological implications, in line with this year's conference theme of "shaping experiences, shaping society." The outcome of the workshop includes a methodological toolbox for researchers working towards empowerment of children and other vulnerable users, with an aim to enable inquiry, design, and critical examination of children's socio-technological futures.

CCS CONCEPTS $•$ Social and professional topics $\sim$ User characteristics $\sim$ Age $\sim$ Children $\bullet$ Human-centered computing $\sim$ Human computer interaction $(\mathrm{HCl}) \sim \mathrm{HCl}$ design and evaluation methods

Additional Keywords and Phrases: Researchers Toolbox, Empowerment and Children, Critical Design Methods, Socio-Technological Futures

To cite the article:

Sirkku Kotilainen, Jussi Okkonen, Guna Spurava, Ole Sejer Iversen, Netta livari, Marianne Kinnula, and Sumita Sharma. 2020. Researchers' Toolbox for he Future: Empowering Children to Shape Their Future. In proceedings of the 11th Nordic Conference on Human-Computer Interaction: Shaping Experiences, Shaping Society (NordiCHI '20), October 25-29, 2020, Tallinn, Estonia. ACM, New York, NY, USA, 3 pages. https://doi.org/10.1145/3419249.3420082

\section{INTRODUCTION}

While much of previous research in Human-Computer Interaction $(\mathrm{HCl})$, and more specifically Child-Computer Interaction $(\mathrm{CCl})$, discusses empowerment of children and other vulnerable groups through their technology use, design, and making, yet the experience, impact, ethics and politics of empowerment are still under-explored (Ames et al. 2014, Kinnula et al. 2017, livari \& Kuutti 2018, Kinnula \& livari 2018)). Questions emerge such as what does it mean to empower children, where are we currently on this quest towards empowerment, and where 
are we headed or aiming for in the future? Empowerment is a multifaceted concept with different disciplines employing and understanding it differently (see e.g. Kinnula et al. 2017, Rajanen \& livari 2019). Within the context of $\mathrm{CCl}$, different forms of empowerment are identified - critical, mainstream, functional, democratic, and empowerment as learning and competence development (Kinnula et al., 2017). While learning and competence development (providing skills and competencies that enable participation in society), functional (providing tools for improving lives) and mainstream (increasing decision-making regarding day to day experiences) forms of empowerment have been in the focus of previous work in $\mathrm{HCl}$ and $\mathrm{CCl}$, the democratic (improved decision-making powers) and critical (questioning the status quo to gain more power and control) forms of empowerment are less studied. This workshop focuses specifically on the critical form of empowerment, the essence of which lies in the power-weak questioning and challenging the status quo to gain more power and control over their own lives and destiny. Methods such as critical design and design fiction (Bardzell \& Bardzell 2013, Blythe 2014), speculative design (Lukens \& DiSalvo 2012, Auger 2013), and other future oriented design approaches, will be explored.

Digital means of participation are central issues as well as children and youth as empowered actors, even at-risk youth (e.g. Pienimäki \& Kotilainen, 2018). This workshop contributes to discussions on the impact of technology use, design, and making on children's educational and career trajectories, and lives in general, not only on their participation in some particular project (Druin 2012, Iversen et al. 2017, Kinnula \& livari 2019), i.e., children shaping their lives with technology, in line with the conference theme. In addition, the workshop aims to approach how digital environments are augmenting their sphere of activities with new affordances as well as opportunities. We focus on the need for collaborating with children and youth as empirical experts in research to help them to get more control over their own lives in the era of datafication (Livingston, 2019), but also for the sake of increasing the validity and robustness of the research. We further ask, how can we realize this and what kinds of ethical aspects should be considered?

In this workshop, we will take stock of the past research on empowerment of children within $\mathrm{HCl} / \mathrm{CCl}$ and combine a strategy-driven process with a future-oriented lens, creating a researchers' toolbox for shaping experiences of society in the future. The main goals of the workshop include:

- Reflecting on previous research on empowerment of children through technology use and design.

- Exploring future-oriented methods and examining how they can be adapted to design with children their technological future lives, with a focus on:

○ their advantages and limitations within the context of empowerment of children

- ethical aspects in participatory methods entailing co-design with children

- devising future pathways and defining ways for monitoring progress

- creating an agenda for future research in this domain

The workshop outcomes include a compilation of a set of hands-on tools and methods, with their pros and cons, that can be employed by researchers working towards designing and shaping the future with children.

\section{PLANNED STRCUTURE}

The workshop consists of two 2-hour sessions, where participants work in teams of 3-4. Each team will be provided pens, papers, and other material to write and draw during the activities. At the end of the workshop, a 30-minute paper writing planning and discussion is held for those participants who are interested. 
Table 1: Planned Sessions Outline

\begin{tabular}{|c|c|}
\hline Session 1 (120 minutes) & Session 2 (120 minutes) \\
\hline $\begin{array}{l}\text { Introduction to the workshop goals and agenda. } \\
\text { Participant introductions and ice-breaker } \\
\text { (20+20 minutes) }\end{array}$ & $\begin{array}{l}\text { Introduction to future-oriented methods } \\
\text { (30 mins) }\end{array}$ \\
\hline $\begin{array}{l}\text { Group Activity: where are we now and how did we get here? } \\
\text { ( } 30 \text { mins) } \\
\text { The focus is on methods that engage, empower, involve, and allow } \\
\text { for co-designing and co-creating together with children. }\end{array}$ & $\begin{array}{l}\text { Group Activity: designing for the future }(40 \text { mins) } \\
\text { The focus is on the following: } \\
\text { - Vision and goals: Where do we want to be? } \\
\text { - } \quad \text { Approach: How are we going to get there? } \\
\text { - Motivations and Drivers: Who is going to do what? } \\
\text { - Success metrics: How will we monitor our } \\
\quad \text { progress? }\end{array}$ \\
\hline Discussion on activity (30 mins) & Discussion on activity (30 mins) \\
\hline Session wrap-up (20 mins) & Session wrap-up (20 mins) \\
\hline
\end{tabular}

\section{CALL FOR PARTICIAPTION}

In this full-day workshop, we approach the vision of children's empowerment by reflecting on the past and taking stock of the present research in $\mathrm{HCl}$ focused on designing and shaping children's technological futures. We invite researchers, designers, and practitioners, interested in empowering children by exploring and imagining technological futures with and for children. We also invite researchers who have an interest in critical design, design fiction, speculative design, and other future oriented design approaches.

Please submit a short position paper (in the SIGCHI extended abstract layout, max 4 pages) by filling in the form on the workshop website. In the paper, please mention author names and affiliations and give a short description of your research interests, driving values and motivations, goals, and your vision for the future of your own research and children's role in designing their technology-rich everyday life, overall. Please elaborate in particular on how your work addresses empowerment of children and in which sense. You can also provide an overview of a study, project, or research paper that you are most proud of in this respect and discuss how the topic of the workshop aligns with your research domain and interests. Please feel also free to mention a method that you would like to bring with you to the workshop (not mandatory).

For more information, please visit the workshop website: https://interact.oulu.fi/researcherstoolbox

\section{PROMOTIONAL STRATEGY}

The workshop will be advertised on social networks (Linkedln, Twitter, Facebook) and the CfP circulated to relevant digital peer groups and emailing lists to recruit interested participants. The workshop webpages will have additional information, such as relevant readings on future-oriented methods, to engage participants before the conference. Workshop participants will be invited to co-author a paper on the outcomes of the workshop (researchers' toolbox) and the workshop website will be updated to reflect the main findings from the workshop. The workshop seeks to bring together $\mathrm{HCl}$ experts, educationists, and practitioners working on critical design and technology with children and other user groups. Further, a series of such workshops, e.g., to $\mathrm{CHI}$ and other relevant venues, are planned to continue refining the researchers' toolbox for the future. 


\section{INSTRUCTORS}

Dr. Netta livari is a Professor in Information Systems and research unit leader of INTERACT Research Unit in University of Oulu. She has a background in Cultural Anthropology as well as in Information Systems and $\mathrm{HCl}$. Her long-lasting research interest concerns empowerment of children in and through design and technology. Her research is strongly influenced by interpretive and critical research traditions. Currently, she is examining critical design and Making in collaboration of children.

Dr. Ole Sejer Iversen is Professor in Interaction Design and Director of Center for Computational Thinking and Design at Aarhus University. His research lies at the intersection of Interaction Design and Child-Computer Interaction with a special interest in participatory practices that support children's digital empowerment.

Dr. Marianne Kinnula is an Associate Professor of human-centred design and digitalization in INTERACT Research Unit in University of Oulu. Her research focus is on how technology changes our everyday lives in many ways, at society level, organizational level, as well as at individual level. She is interested in children's genuine possibility to affect the decisions that concern them as well as their technology-rich environment.

Dr. Sirkku Kotilainen is professor of media education at the Faculty of Information Technologies and Communication Sciences at Tampere University, Finland. Her research focuses on children and youth as users online and their digital literacies. More recently, her research has focused on promoting digital literacy among at-risk youth and methodological developments in co-research with young people as empirical experts in their uses of technology.

Dr. Jussi Okkonen is Adjunct Professor of sociotechnical environments and he works currently as Senior Research Fellow in Faculty of Information Technologies and Communication Sciences at Tampere University, Finland. Lately Okkonen has put more emphasis on extended, augmented, asynchronic and spatially dispersed work and humans in digital environments. The underlying theme still is the individual and organizational performance connected to information ergonomics.

Dr. Sumita Sharma is a post-doc researcher at the INTERACT Research Unit at the University of Oulu. Her research work focuses on designing inclusive and collaborative technology for the classroom environment for children across the world, including children living in urban slums, children with special needs, and children in remote communities, and studying socio-technical opportunities for empowerment of children.

Guna Spurava is a project researcher at Faculty of Information Technologies and Communication Sciences at Tampere University, Finland. She is working on the development of media education research focusing on teachers' and librarians' role as mediators of media literacy. Also she works on research of young people's media usage and she is interested in co-research with young people as empirical experts.

\section{ACKNOWLEDGMENTS}

This work is funded by the Academy of Finland (Grant \#324685, Make-a-Difference project) and by European Union's Horizon 2020 Research and Innovation programme (Grant \#787476, COMnPLAY SCIENCE project) at the University of Oulu. This research is connected to the GenZ project, a strategic profiling project in human sciences at the University of Oulu. The project is supported by the Academy of Finland (Grant \#318930) and the University of Oulu.

At Tampere University, this work is funded by two European Union's Horizon 2020 programs: CO:RE (H2020-SC6-TRANSFORMATIONS-2019, grant \# 871018) and SEIS (H2020-WIDESPREAD-2018, grant \# 856954). 


\section{REFERENCES}

Morgan Ames, Jeffrey Bardzell, Shaowen Bardzell, Silvia Lindtner, David A. Mellis, and Daniela K. Rosner. 2014. Making cultures: empowerment, participation, and democracy-or not? In CHI'14 Extended Abstracts on Human Factors in Computing Systems. ACM, 1087-1092.

James Auger. 2013. Speculative design: crafting the speculation. Digital Creativity, 24:1, 11-35.

Jeffrey Bardzell and Shaowen Bardzell. 2013. What is "critical" about critical design? In Proceedings of the SIGCHI conference on human factors in computing systems. ACM, 3297-3306.

Mark Blythe. 2014. Research through design fiction: narrative in real and imaginary abstracts. In Proceedings of the SIGCHI conference on human factors in computing systems. ACM, 703-712.

Allison Druin. 2002. The role of children in the design of new technology. Behaviour and information technology, 21.1: 1-25.

Netta livari and Kari Kuutti. 2018. Critical design in interaction design and children: impossible, inappropriate or critical imperative? In Proceedings of the Conference on Interaction Design and Children. ACM, 456-464.

Netta livari and Marianne Kinnula. 2018. Empowering Children through Design and Making - towards Protagonist Role Adoption. In Proceedings of the International Conference on Participatory Design (PDC'18).

Sonia Livingstone. 2019. Audiences in an Age of Datafication: Critical Questions for Media Research. Television \& New Media, 20(2), 170183.

Jonathan Lukens and Carl DiSalvo. 2012. Speculative design and technological fluency. International Journal of Learning and Media, 3:4.

Ole Sejer Iversen, Rachel Charlotte Smith, and Christian Dindler. 2017. Child as protagonist: Expanding the role of children in participatory design. In Proceedings of the Conference on Interaction Design and Children. ACM, 27-37.

Marianne Kinnula, Netta livari, Tonja Molin-Juustila, E. Keskitalo, T. Leinonen, E.Mansikkamäki, T. Käkelä, and M. Similä. 2017. Cooperation, Combat, or Competence Building - What Do We Mean When We Are 'Empowering Children' in and through Digital Technology Design? In Proceedings of the Thirty eighth International Conference on Information Systems.

Marianne Kinnula and Netta livari. 2019. Empowered to Make a Change: Guidelines for Empowering the Young Generation in and through Digital Technology Design. In Proceedings of the FabLearn Europe 2019 conference. ACM, 16.

Mari Pienimäki and Sirkku Kotilainen. 2018. "Youth Participation in Research on Multiliteracies: Ethical Perspectives". Media Education Research Journal MERJ, 8:1, 115-132.

Mikko Rajanen and Netta livari. 2019. Empowered or Disempowered? An Analysis of Usability Practitioners' Interventions in Open Source Projects. J. Leroux (Ed.) Psychological Perspectives on Empowerment. 